\title{
Perancangan Sistem Informasi Pemasaran Pada AO Chicken
}

\author{
Khalimaturofi'ah \\ Email : imelzgadiz27@gmail.com \\ Sekolah Tinggi Manajemen Informatika dan Komputer Tunas Bangsa Banjarnegara
}

\begin{abstract}
Abstrak
AO Chicken merupakan usaha rumahan dalam bidang pengolahan makanan jadi. Saat ini, pemasaran pada AO CHICKEN masih dilakukan secara manual yakni melalui mulut ke mulut, memanfaatkan sarana telepon, sms, dan aplikasi whatsapp. Pemasaran dilakukan dengan memasang status/story whatsapp terkait produk makanan yang dijual dan menerima pesanan melalui aplikasi tersebut sehingga pemasaran jarak jauh dan yang belum memiliki kontak pemilik usaha mengalami kesulitan apabila ingin melihat produk makanan yang di jual, untuk pengontrolannya secara langsung (online) belum ada, dan belum terkomputerisasi. Tujuan penelitian ini adalah untuk menganalisis dan merancang sistem informasi pemasaran pada AO CHICKEN berbasis e-commerce. Metode pengumpulan data yang dilakukan adalah dengan metode wawancara, observasi, dan partisipasi. Perancangan sistem menggunakan Flowchart, DFD (Data Flow Diagram) dan Perancangan Tabel Relasi. Hasil penelitian adalah sebuah perancangan sistem informasi untuk memasarkan sebuah produk makanan berbasis e-commerc.
\end{abstract}

Kata kunci : Perancangan, Sistem, Pemasaran, DFD, E-commerce

\section{Pendahuluan}

AO Chicken merupakan usaha rumahan dalam bidang pengolahan makanan jadi yang beralamat di Desa Kertayasa Kabupaten Banjarnegara. Produk makanan yang dijual oleh AO CHICKEN diantaranya Ayam Geprek, Ayam Goreng Tepung, Mie Ayam, Bakso, Nasi Goreng, dan Bakmie Goreng. Berdasarkan hasil pengumpulan data yang dilakukan, pemasaran pada AO CHICKEN masih dilakukan secara manual yakni melalui mulut ke mulut, memanfaatkan sarana telepon, sms, dan aplikasi whatsapp. Pemasaran dilakukan dengan memasang status/story whatsapp terkait produk makanan yang dijual dan menerima pesanan melalui aplikasi tersebut sehingga pemasaran jarak jauh dan yang belum memiliki kontak pemilik usaha mengalami kesulitan apabila ingin melihat produk makanan yang di jual. Tujuan dari penelitian ini adalah menganalisis dan merancang sistem informasi pemasaran berbasis web pada AO CHICKEN untuk meningkatkan pemasaran sehingga menambah pendapatan dan mengurangi biaya pemasaran. Menurut Fandy Tjiptono ( 2015 ; 11 ), Pemasaran adalah penentuan apa yang akan dijual kepada konsumen berupa produk atau jasa dengan mendapatkan laba, melalui caracara tertentu dan penciptaan dan pengolahan program untuk menghasilkan, melayani dan memperluas penjualan. Menurut Zeithaml, dkk (2013 ;24), Bauran pemasaran terdiri dari semua hal yang dapat dilakukan perusahaan untuk mempengaruhi permintaan akan produknya yang terdiri dari " 7 (Tujuh) P" yaitu: Product, Place, Promotion, Price, People, Physical Evidenve, Process.

\section{Metode Penelitian}

Metode penelitian yang digunakan pada penelitian ini antara lain metode pengumpulan data dan Metode Perancangan Sistem. Pada pengumpulan data, peneliti menggunakan metode wawancara, observasi dan partisipasi. Wawancara yang digunakan peneliti dalam penelitian adalah wawancara tidak terstruktur, yaitu wawancara yang bebas dimana penelitian tidak menggunakan pedoman wawancara yang tersusun secara sistematis dan lengkap untuk pengumpulan datanya. Narasumber wawancara adalah pemilik usaha dan bagian pemasaran. Pada merode pengumpulan data observasi dan partisipasi, peneliti melakukan pengamatan langsung pada proses pemasaran yang dilakukan dan ikut terlibat langsung dalam proses tersebut. Metode Perancangan dilakukan dengan Flowchart, DFD (Data Flow Diagram), dan Rancangan relasi tabel.

\section{Hasil dan Pembahasan}

Peneliti melakukan analisa terhadap sistem yang sedang berjalan, dari analisa yang 
telah dilakukan maka ditemukan beberapa kendala dalam pemasaran yang dilakukan pada Warung AO CHICKEN, diantaranya:

- Pemasaran yang dilakukan masih manual sehingga lambatnya informasi yang di terima konsumen, Hal ini menghambat proses pemasaran dan perluasan pangsa pasar.

- Keterbatasan informasi melalui sms, telepon, aplikasi whatsapp dan dari mulut ke mulut sehingga mengakibatkan Terbatasnya jangkauan wilayah promosi dan penjualan produk yang kurang optimal

- Lambatnya penanganan terhadap proses penjualan dan Pembayaran

Sistem yang saat ini berjalan di AO CHICKEN dapat dilihat pada Gambar 1

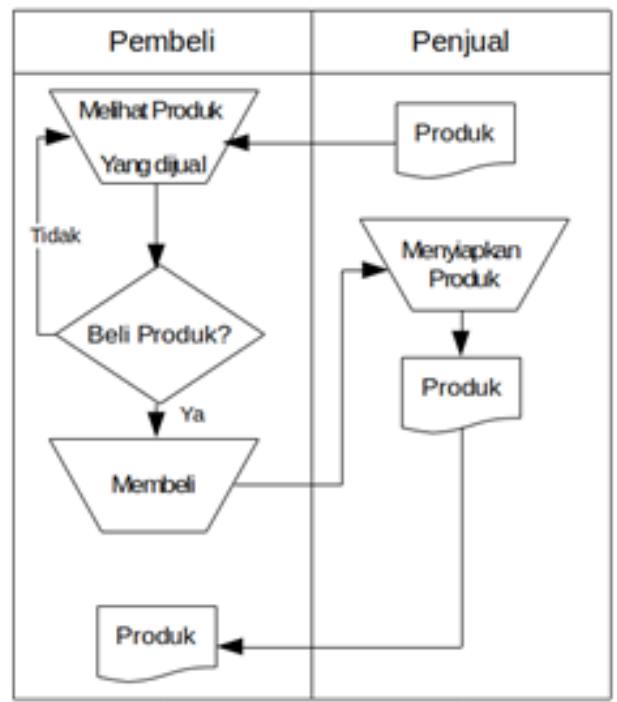

Gambar 1. Sistem berjalan saat ini

Dalam membuat rancangan ini dibutuhkan suatu alat dan bahan penunjang. Spesifikasi penunjang tersebut adalah :

1) Perangkat Keras (Hardware) :

- Processor Intel Celeron, RAM 4GB

- Hard disk dengan space 500 GB

2) Perangkat Lunak (Software) :

- Sistem operasi Windows 10s

- Web Browser

- Dreamweaver

- Ms. Access

- Php

Dalam membangun sistem pemasaran, data yang dibutuhkan diantaranya :

- $\quad$ Data Badan Usaha/Warung

- Data Produk dan Harga

Dari data-data tersebut, diharapkan dapat menghasilkan sebuah sistem informasi pemasaran yang dapat mengelola dalam hal berikut :

- $\quad$ Kelola Data Produk dan Harga

- $\quad$ Kelola Data Badan Usaha/Warung

- Kelola Data Pemesanan

- Kelola Data Pembayan

A. ALUR PENELITIAN

Alur penelitian pada analisa dan perancangan sistem informasi pemasaran pada AO CHICKEN dapat dilihat pada Gambar 2

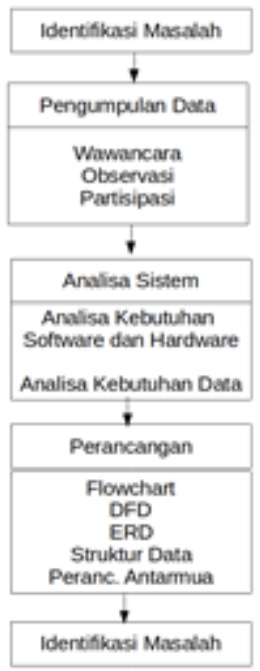

Gambar 2. Alur Penelitian

B. PERANCANGAN SISTEM

1) Flowchart

Perancangan Flowchart digunakan untuk menggambarkan alur bagaimana proses pemasaran dan pemesanan produk pada AO CHICKEN. Perancangan Flowhchart dapat dilihat pada Gambar 3 dan Gambar 4

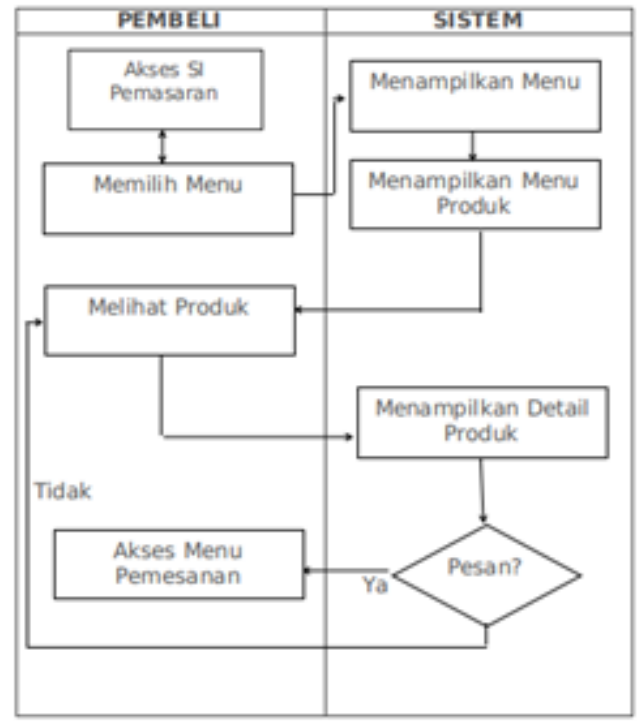

Gambar 3. Flowchart Pemasaran 
Pada Gambar 3 menjelaskan alur proses pemasaran dimana pembeli mengakses S.I Pemasaran untuk mengetahui produk apa saja yang dijual oleh AO CHICKEN. Selanjutnya Pembeli dapat mengakses menu produk untuk mendapatkan informasi mengenai detail produk dan mengakses menu pemesanan apabila ingin memesan produk.

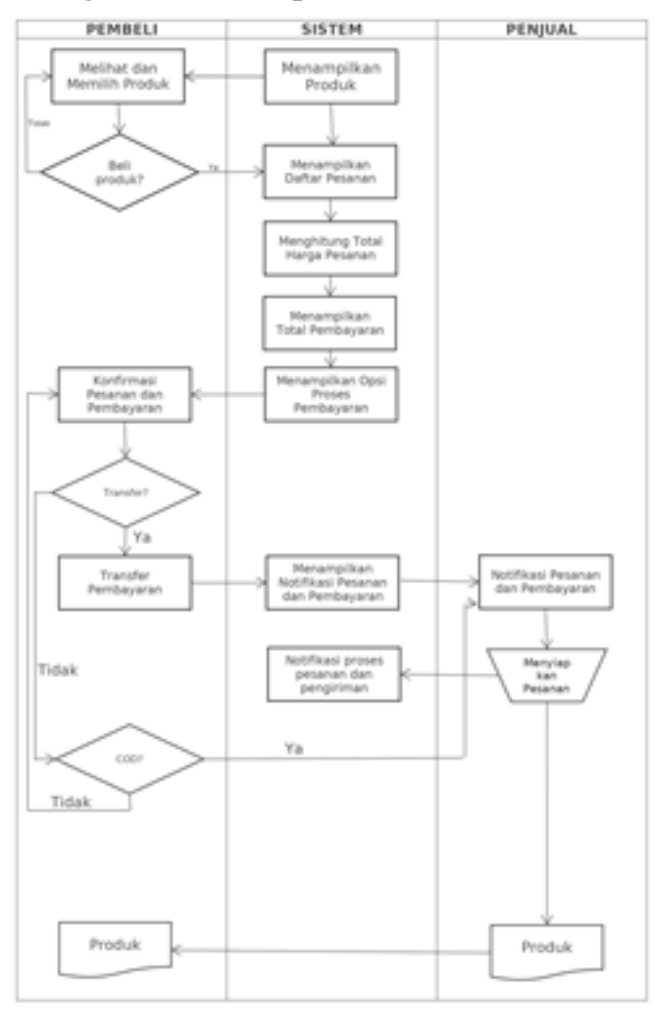

Gambar 4. Flowchart Proses Pemesanan

Pada Gambar 4 menjelaskan alur bagaimana proses pemesanan dilakukan melalui sistem pemasaran. Pembeli melihat langsung produk-produk makanan yang dijual di AO CHICKEN yang ditampilkan oleh sistem, Pembeli memilih dan memesan produk makanan, sistem memberikan konfirmasi daftar pemesanan dan jumlah yang harus dibayar oleh pembeli dan memberikan pilihan metode pembayaran yang akan digunakan. Ada 3 metode yaitu secara langsung apabila pembeli datang langsung ke Warung AO CHICKEN, metode transfer apabila pembeli memesan makanan lewat sistem pemasaran dan pembayaran dilakukan dengan transfer, dan COD apabila pembeli menghendaki pembayaran dilakukan setelah makanan sampai ke pembeli. Setelah proses pembayaran selesai, sistem akan memberikan notifikasi kepada penjual bahwa ada pesanan masuk agar penjual segera menyiapkan pesanan pembeli, sistem akan memberikan notifikasi bahwa pesanan sedang disiapkan dan akan segera dikirim.

2) DFD (Data Flow Diagram)

Data Flow Diagram di rancang untuk memberikan gambaran kepada user sistem tentang bagaimana proses/prosedur dan urutan sistem dalam menyelesaikan permasalahan. DFD Sistem informasi pemasaran pada AO Chicken dapat dilihat pada Gambar 5 dan Gambar 6

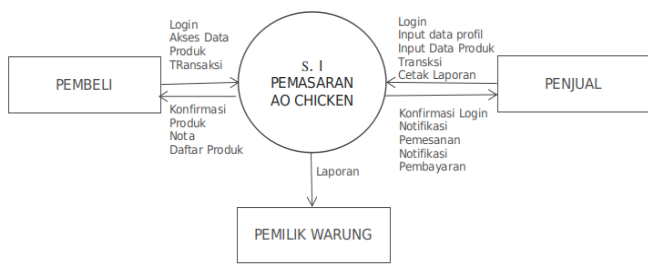

Gambar 5. Diagram Konteks Sistem Informasi Pemasaran AO Chicken

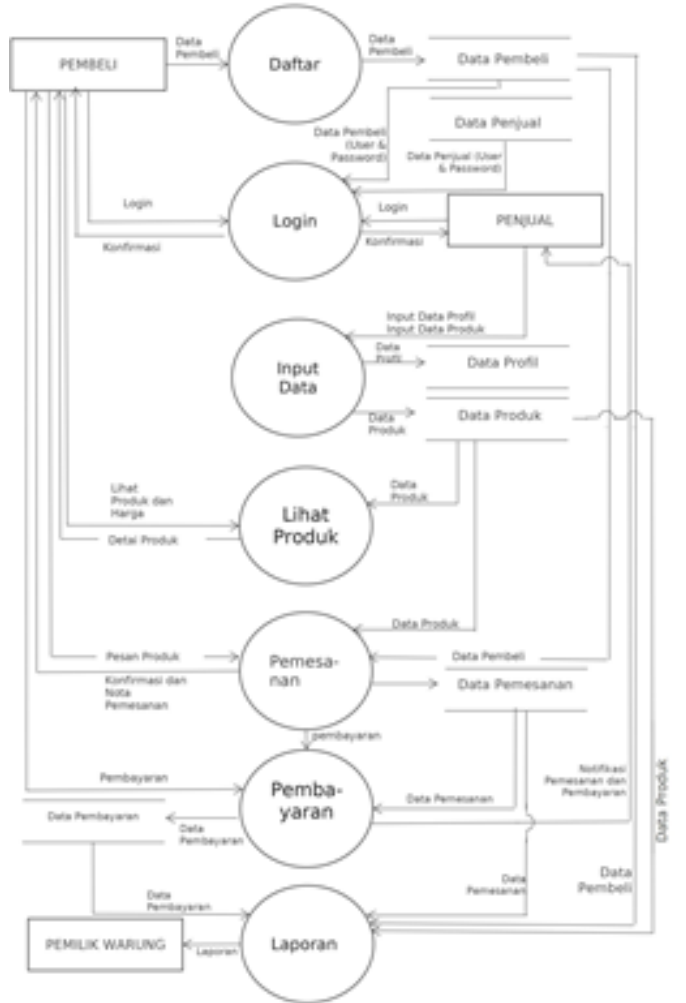

Gambar 6. DFD level 1 S. I Pemasaran AO CHICKEN

3) Relasi Tabel

Relasi antar tabel Sistem Informasi Pemasaran pada AO CHICKEN dapat dilihat pada Gambar 7 


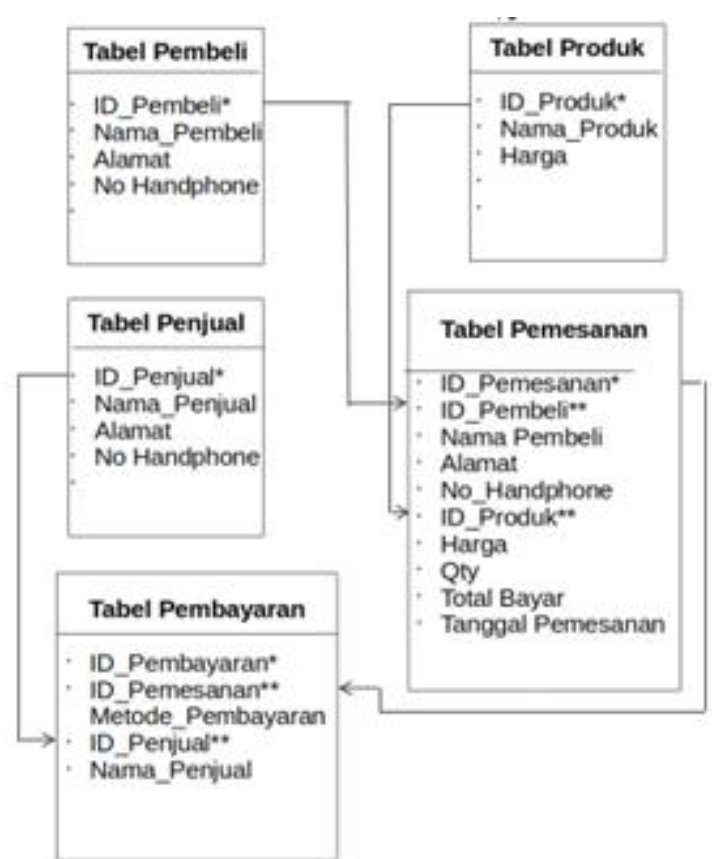

4) Perancangan Antarmuka

Perancangan antarmuka dibuat agar user memiliki gambaran tentang tampilan sistem sehingga dapat memberikan masukan sesuai dengan keinginan dan kebutuhan user. Adapun desain antarmuka Sistem Informasi Pemasaran pada AO CHICKEN dapat dilihat pada Gambar 8 sampai Gambar 11

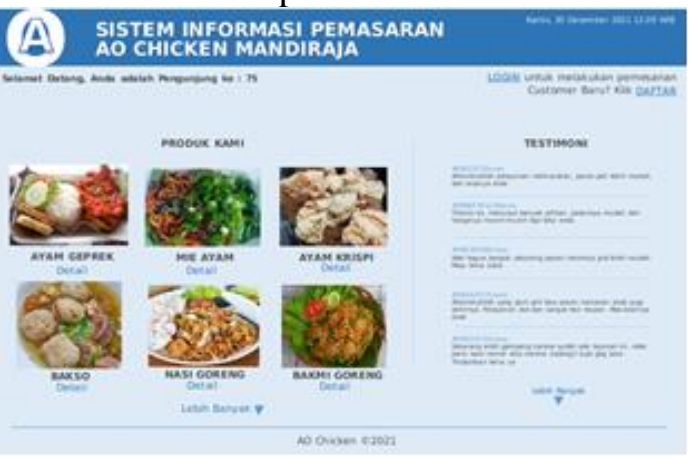

Gambar 8. Tampilan Antarmuka Beranda Untuk

$$
\text { Pembeli }
$$

Pada halaman beranda ditampilkan menu-menu atau produk yang ada di $\mathrm{AO}$ CHICKEN sehingga pelanggan dapat melihat secara detail produk yang dijual.

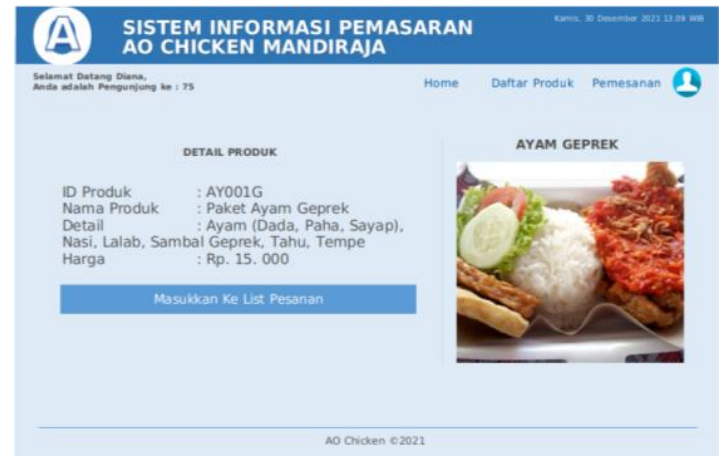

Gambar 9. Menu Detail Produk

Untuk melihat detail produk, pelanggan bisa Login terlebih dahulu maupun tidak. Jika sudah Login, saat pelanggan akan memesan produk/menu yang ditampilkan sistem maka hanya melanjutkan proses dengan memilih menu Masukkan ke List Pesanan, Namun jika belum login maka sistem akan mengarahkan untuk melakukan proses login atau daftar apabila pelanggan belum memiliki akun.

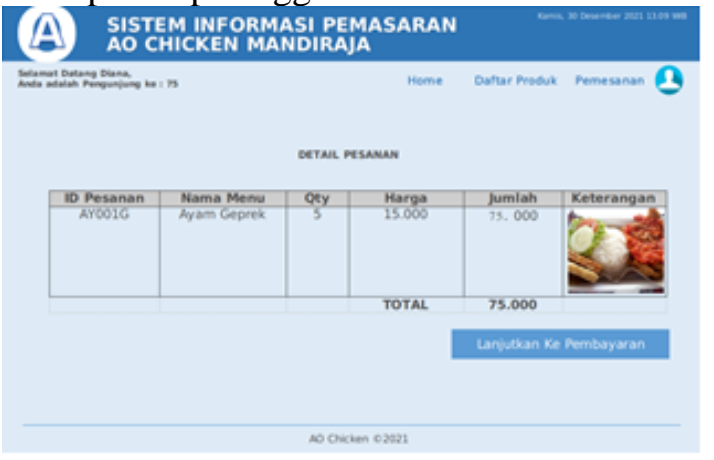

Gambar 10. Desain Antarmuka Menu Pemesanan (A) SISTEM INFORMASI PEMASARAN

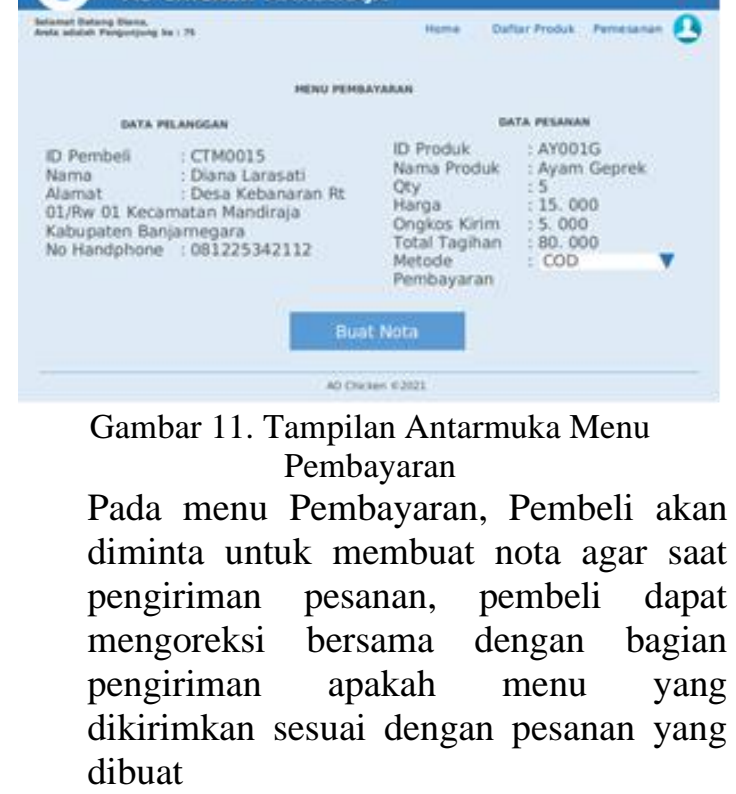




\section{Kesimpulan}

Berdasarkan hasil penelitian maka dapat diambil kesimpulan sebagai berikut :

1) Hasil analisa menunjukkan bahwa $\mathrm{AO}$ CHICKEN perlu menerapkan model pemasaran yang baik meliputi proses pengelolaan produk, pemesanan dan pembayaran.

2) Perancangan ini diharapkan bisa membantu AO CHICKEN untuk memperoleh peluang dalam pengembangan jaringan pemasaran tidak terbatas daerah lokal saja.

3) Rancangan Sistem Informasi Pemasaran ini bertujuan untuk memberikan layanan bagi konsumen agar dapat secara langsung melakukan transaksi kapanpun dan dimanapun.

Saran perlu pengembangan versi produksi dan dilakukan evaluasi agar dapat diterapkan di AO CHICKEN sehingga membantu dalam proses pemasaran dan transaksi

\section{Daftar Pustaka}

[1] Adelheid, A., ; Khairil, Nst., Buku Pintar Menguasai PHP Dan Mysql, Penerbit Mediakita, Jakarta Selatan 12630.

[2] Arikunto, Suharsimi, 1998, Prosedur Penelitian Suatu Pendekatan Praktek. Penerbit PT RINEKA CIPTA, Jakarta.

[3] Hanif, FA., 2007, Analisis dan perancangan sistem informasi untuk keunggulan bersaing Bisnis moderen, Penerbit PT ANDI, Yogyakarta.

[4] Hartami Santi, Indyah., 2020, Analisa Perancangan Sistem, Penerbit PT. Nasya Expanding Management, Pekalongan Jawa Tengah

[5] Hutahaean, J., 2014, Konsep Sistem Informasi. Penerbit Deepublish: Yogyakarta.
[6] Latubessy, Anastasya., Triyanto, Wiwit Agus., Analisa dan Perancangan Sistem Informasi Pemasaran UMKM Terintegrasi Berbasis Cloud Server, Vol 5 No 1 April 2014 ISSN: 2252-4983, Jurnal SIMETRIS

[7] Mincarti, Iis., Mulyono, Herry., Analisis dan Perancangan Sistem Informasi Pemasaran perumahan syariah berbasis web pada PT. Lestari Berkah Abadi, Vol. 5, No.4, Desember 2020, ISSN : 25280082, Jurnal MANAJEMEN SISTEM INFORMASI

[8] Nugraha, Fajar., Analisa dan Perancangan Sistem Pemasaran Berbasis E-commerce Untuk Pemasaran Produk UMKM, Volume 5 No 3 - Agustus 2016, ISSN : 2302-5700 (Print) - 2354-6654 (Online), Indonesian Journal on Networking and Security

[9] Rahman Prehanto, Dedy., 2020, Buku Ajar Konsep Sistem Informasi, Penerbit SCOPINDO, Surabaya

[10] Rahmawati, Noni., Mulyono, Herry., Analisis dan Perancangan Sistem Informasi Pemasaran berbasis web pada Toko Billy, Vol 1 No. 2, Desember 2016 ISSN : 2540-8011, Jurnal Manajemen Sistem Informasi

[11] Romli, M., ; Syamsul, A., 2012, Panduan Praktisi Mengelola Media Online.Penerbit Jurnalistik Online, Bandung.

[12] Susanti, Nanik., Perancangan EMarketing UMKM Kerajinan Tas, Vol. 9 No. 1 April 2018, ISSN: 2252-4983, Jurnal SIMETRIS

[13] Zaliludin, Dadan., Rohmat, Perancangan Sistem Informasi Penjualan Berbasis Web ( Studi Kasus Pada NEWBIESTORE), Volume 4 Nomor 1 Tahun 2018, ISSN : 2460-1861, INFOTECH Jurnal 